\title{
Prognosis of a case with paresthesia associated with prolonged touching of an endodontic paste to the inferior alveolar nerve
}

\author{
M. Cemil Buyukkurt ${ }^{1}$, Hakan Arslan ${ }^{2}$, H. Sinan Topcuoglu ${ }^{2}$, M. Melih Omezli ${ }^{3}$ \\ ${ }^{1} \mathrm{PhD}$, DDS. Department of Oral and Maxillofacial Surgery, Faculty of Dentistry, Sifa University, İzmir, Turkey \\ ${ }^{2}$ DDS. Department of Endodontic, Faculty of Dentistry, Ataturk University, Erzurum, Turkey \\ ${ }^{3}$ DDS. Department of Oral and Maxillofacial Surgery, Faculty of Dentistry, Ataturk University, Erzurum, Turkey
}

Correspondence:

Department of Endodontic,

Faculty of Dentistry,

Ataturk University,

Erzurum, 25240, Turkey

E-mail address: dt_hakan82@hotmail.com

\begin{abstract}
Paresthesia is described as an abnormal sensation, such as burning, pricking, tickling, tingling, formication or numbness. Several conditions can cause paresthesia. This article presents a case of paresthesia caused by the extrusion of endodontic paste (Endomethasone ${ }^{\mathbb{R}}$ ) into the mandibular canal. The clinical manifestations comprised the numbness on the right side of the mandible and right lower lip, appearing after endodontic treatment. After a mandibular block and infiltration anesthesia a mucoperiostal flap was raised and the extruded Endomethasone ${ }^{\circledR}$ was removed successfully. A therapy with antibiotic, B vitamin complex and an analgesic were prescribed. The patient reported an improvement in pain and headache after one week later and in burning after two weeks. After a four months follow-up, she became symptom free. Also sixteen months later she had any symptoms. Normalization of sensation shows that the neurotoxic effects of Endomethasone ${ }^{\circledR}$ are reversible after more than one month from the first touch of Endomethasone ${ }^{\circledR}$ to the inferior alveolar nerve.
\end{abstract}

Key words: Endomethasone, inferior alveolar nerve damage, paresthesia, root canal treatment. 


\section{Introduction}

Sensory disturbances include anesthesia, hypoesthesia, hyperesthesia, and paresthesia. In senses are affected at the same time (1). Paresthesia is described as an abnormal sensation, such as burning, pricking, tickling, tingling, formication or numbness. Systemic diseases such as viral infections, multiple sclerosis, syphilis, metastatic malignancy, bone infections, tumors, oral surgery, fractures, periapical lesions, injections, or endodontic treatment can cause paresthesia (1-3).

The principles of endodontic treatment are the elimination of infected pulp and dentin, adequate root canal preparation and sealing. Nevertheless, over - instru- mentation of the root canal can perforate the mandibular canal. As a result of this undesirable condition three possible mechanisms can be envisaged: 1. mechanical trauma on the inferior alveolar nerve by the instruments or obturation materials; 2 . neurotoxic effects from the medicaments, irrigation or the obturation materials; 3 . thermal factors due to a lack of mastery in the thermo compaction filling techniques (4-6).

The following report presents the surgical treatment of a paresthesia case that followed the inattentive extrusion of Endomethasone ${ }^{\circledR}$ root canal sealer into the inferior alveolar canal.

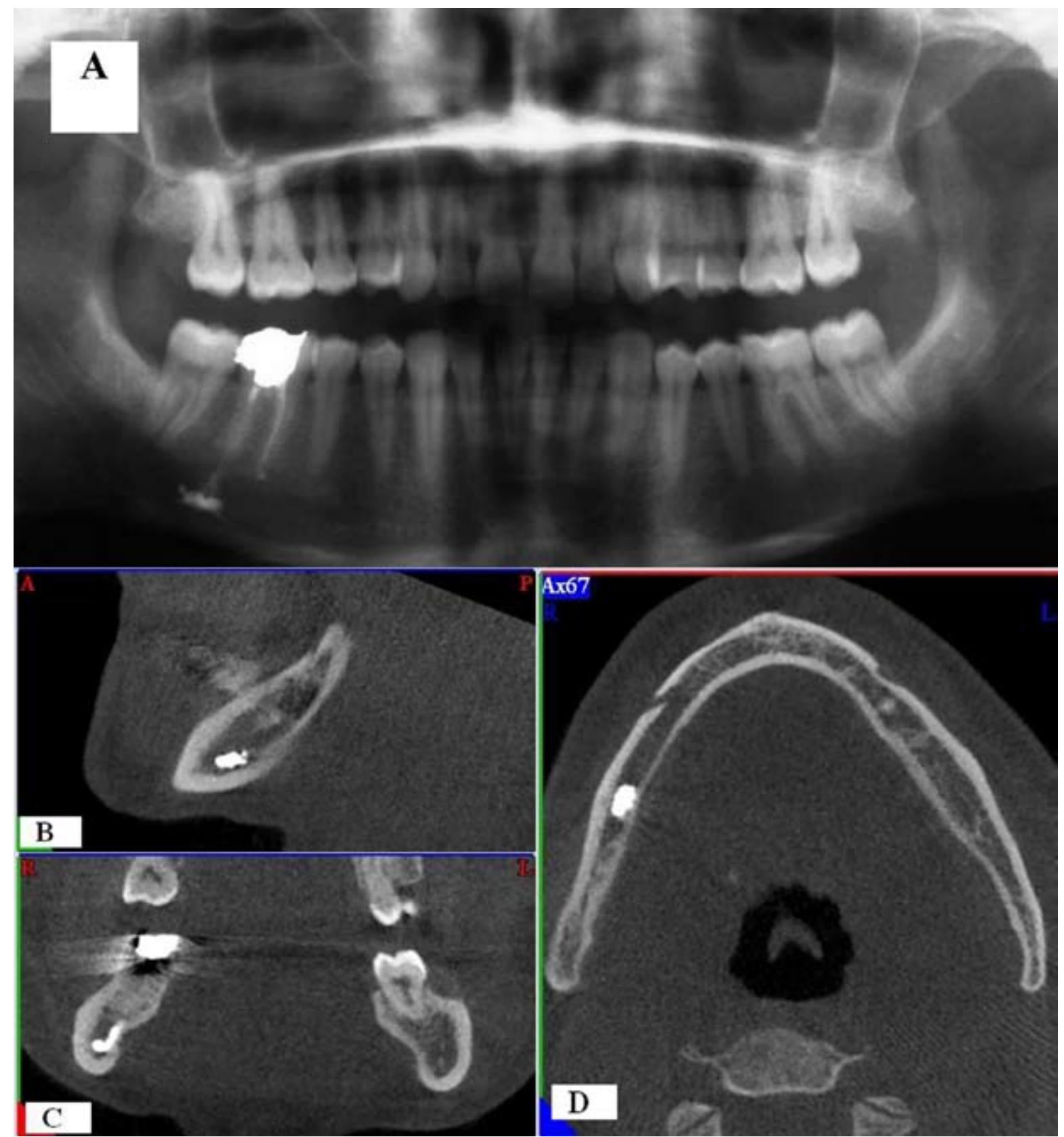

Fig. 1. Preoperative panoramic radiograph (A), CT scan images (B, C and D), showing extruded material around the apex of the lower right first molar tooth. 


\section{Case Report}

A 23-year old woman suffering from severe pain and paresthesia in the right side of the mandible and the lower portion of the lip was referred to the Endodontics Department of Ataturk University. The patient reported that her local dentist had performed root canal treatment in her right first mandibular molar four weeks earlier. She had returned to the dentist with the numbness on the right side of the mandible and right lower lip the following day. The dentist had decided to wait for one week for a possible spontaneous recovery. Two weeks after the procedure, there were no signs of recovery; additionally, she reported to her dentist burning and sensitivity of the lower right-side chin and lip zones. She was given a prescription for antibiotics and analgesics by her dentist. No further treatment was carried out. After one month the patient's spontaneous pain became more intense and disabling, and she decided to apply to Dentistry faculty of Ataturk University.

The patient's medical history of patient was uneventful. No swelling, redness, or other signs of infection were observed at intra oral examination and extra oral examination. The anesthetized zone was delimited by tactile exploration. The lower lip was not painful to touch.
However, she pointed out the burning sensation was increased at night and also when an object touched. Panoramic radiograph (Fig. 1A) revealed the presence of radiopaque material in the periapical area of the lower right first molar tooth. The computed tomography (Fig. $1 \mathrm{~B}, \mathrm{C}, \mathrm{D})$ confirmed the presence of radiopaque material in the periapical area of the lower right first molar tooth. We contacted the dentist, who explained that the filling of the root canal had been done using Endomethasone $^{\circledR}$. The product had been introduced within the canal by using a lentulo spiral. It was decided that tooth 26 should be extracted and an attempt made to remove the extruded Endomethasone ${ }^{\circledR}$ through the alveolus. The patient was scheduled for surgery five days later.

Five days later the patient's pain became much more intense and the patient reported a headache. After informing the patient of all possible complications that can occur during and after the surgery, a signed consent form was obtained from the patient. The patient was administered a mandibular block and infiltration anesthesia (Ultracain D-S Forte ${ }^{\circledR}$, Aventis, Turkey). First, the molar tooth was extracted. Then, the buccal mucoperiostal flap was raised and the buccal cortical bone was removed using a bur and adequate coolant. This allowed access

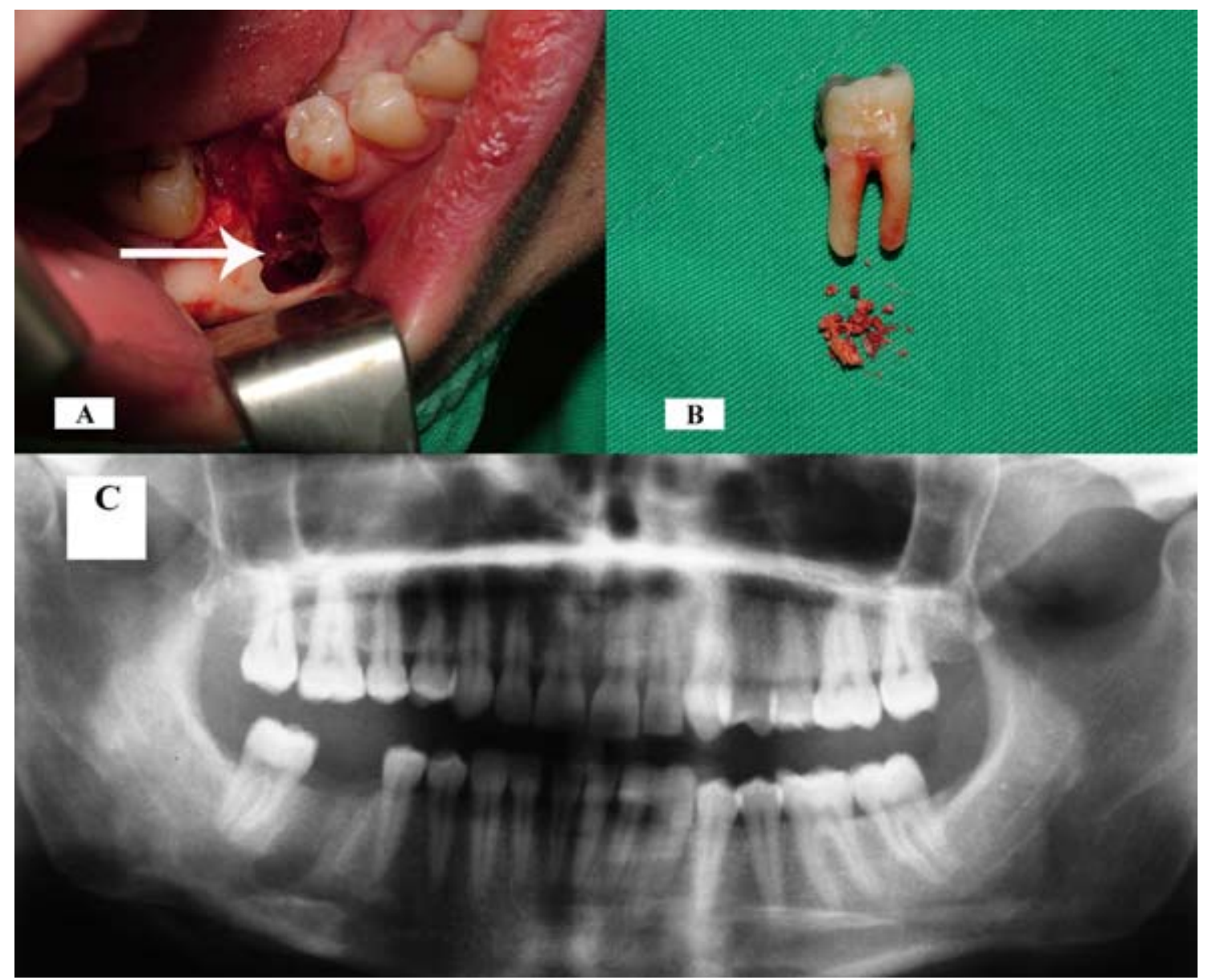

Fig. 2. Intraoperative view showing inferior alveolar nerve (A, white arrow), the photograph showing extracted tooth and removed the sealer $(B)$, panoramic radiograph exposed after the surgery showing clear area $(C)$. 
to the periapical area, which was needed to remove the foreign body. The inferior alveolar nerve was gently retracted to clean all the sealer from the canal. There was sealer material at the periphery of the nerve. The sealer on the nerve and in the canal was removed (Fig. 2A). The flap was repositioned and sutured in place. Following surgery, panoramic radiographs (Fig. 2B) confirmed satisfactory removal of the Endomethasone ${ }^{\circledR}$ from the mandibular canal. A therapy with antibiotic (amoxicillin + clavulanate, $2000 \mathrm{mg}$ /day), B vitamin complex (vitamin B1, B6 and B12, 1, $5 \mathrm{mg} /$ day), and an analgesic (naproxen sodium, $1100 \mathrm{mg} /$ day) were prescribed. The patient reported an improvement in pain and headache after one week later and in burning after two weeks. After a four-month follow-up, she became symptom free. Also sixteen months later she had any symptoms.

\section{Discussion}

Endodontic procedures such as local anesthesia, overinstrumentation, and overfilling have a possible risk for paresthesia. Moreover, Zmener (7) has reported a mandibular nerve paresthesia which was associated with an adhesive resin restoration placed in direct contact with the pulp of a mandibular molar. He added in his report that a possible allergic reaction to the adhesive resin could be the main cause of the paresthesia. It is expected that the mandibular paresthesia related to the local anesthetics or endodontic overinstrumentation is normally resolved within a few days (6). In overfilling cases, while some authors reported that patients recovered spontaneously without surgical removal of endodontic paste, some others reported that recovery was seen with surgical removal of endodontic paste $(8,9)$.

In some studies zinc oxide, eugenol, and calcium hydroxide have been shown to be neurotoxic. That paraformaldehyde and eugenol are the main material causing neurotoxic reactions has been presented (10). Eugenol is a phenol derivate which can cause chemical destruction of the axon by penetrating the nerve and coagulating the proteins providing that it has sufficient concentration (11, 12). On the one hand, paraformaldehyde is a polymeric hydrate of formaldehyde which releases formaldehyde gas in case of contacting with water at room temperature (8). It is known that Endomethasone ${ }^{\circledR}$ is paste of zinc oxide, paraformaldehyde, eugenol, corticosteroids, thymol iodide, lead oxide, and bismuth subnitrite.

Froes et al. (9) suggested that anti-inflammatory drugs and completing endodontic therapy can be another option instead of immediate surgical intervention. Some authors suggested that the use of corticosteroids may be helpful in reduction compression effects (10). Surgical removal of the filling material from mandibular canal is recommended when the sealer contains cement Paraformaldehyde and in cases of prolonged pain or paresthesia $(8,10,13)$. The surgical treatment options for decom- pression of the inferior alveolar nerve can include extraction of the tooth and cleaning the socket, apicotomy of the overfilled tooth with cleaning around bone, and decortication of the mandible achieved laterally through intraoral approach and sagittal osteotomy. In this case, the buccal mucoperiostal flap was raised and the buccal cortical bone was removed following the tooth extraction.

Tilotta- Yasukawa et al. (4) pointed out that the neurovascular bundle travels through the spongy bone. These researchers did not come across a mandibular canal consisting of a cortical bone. This morphology makes the mandibular pedicle indefensible against various mechanical or chemical elements that may damage it. To prevent the mandibular pedicle from this damage, we consider that the working length should be measured with an electronic apex locator or radiographs. Also the application of a good apical stop and moderate condensation will help avoid overfilling or overextending the endodontic material. Additionally lentulo spirals and other rotary instruments can originate an overextension beyond the apical foramen.

In our case, there were prolonged pain and paresthesia due to the extrusion of Endomethasone ${ }^{\circledR}$ into the mandibular canal. Hence, the decompression surgery was performed. Two weeks after the surgery, burning reduction was observed and four months later. Normalization of sensation shows that the neurotoxic effects of Endomethasone ${ }^{\circledR}$ are reversible after more than one month from the first touch of Endomethasone ${ }^{\circledR}$ to the inferior alveolar nerve.

\section{Acknowledgement}

The authors deny any financial affiliations related to this study or its sponsors.

\section{References}

1. Lambrianidis T, Molyvdas J. Paresthesia of the inferior alveolar nerve caused by periodontal-endodontic pathosis. Oral Surg Oral Med Oral Pathol. 1987;63:90-2.

2. Spielman A, Gutman D, Laufer D. Anesthesia following endodontic overfilling with AH26. Report of a case. Oral Surg Oral Med Oral Pathol. 1981;52:554-6.

3. González-Martín M, Torres-Lagares D, Gutiérrez-Pérez JL, Segura-Egea JJ. Inferior alveolar nerve paresthesia after overfilling of endodontic sealer into the mandibular canal. J Endod. 2010;36:1419-21.

4. Tilotta-Yasukawa F, Millot S, El Haddioui A, Bravetti P, Gaudy JF. Labiomandibular paresthesia caused by endodontic treatment: an anatomic and clinical study. Oral Surg Oral Med Oral Pathol Oral Radiol Endod. 2006;102:e47-59.

5. Pogrel MA. Damage to the inferior alveolar nerve as the result of root canal therapy. J Am Dent Assoc. 2007;138:65-9.

6. Gallas-Torreira MM, Reboiras-Lopez MD, Garcia-Garcia A, Gandara-Rey J. Mandibular nerve paresthesia caused by endodontic treatment. Med Oral. 2003;8:299-303.

7. Zmener O. Mental nerve paresthesia associated with an adhesive resin restoration: a case report. J Endod. 2004;30:117-9.

8. Scolozzi P, Lombardi T, Jaques B. Successful inferior alveolar nerve decompression for dysesthesia following endodontic treatment: 
report of 4 cases treated by mandibular sagittal osteotomy. Oral Surg Oral Med Oral Pathol Oral Radiol Endod. 2004;97:625-31.

9. Froes FG, Miranda AM, Abad Eda C, Riche FN, Pires FR. Nonsurgical management of paraesthesia and pain associated with endodontic sealer extrusion into the mandibular canal. Aust Endod J. 2009;35:183-6.

10. Köseoğlu BG, Tanrikulu S, Sübay RK, Sencer S. Anesthesia following overfilling of a root canal sealer into the mandibular canal: a case report. Oral Surg Oral Med Oral Pathol Oral Radiol Endod. 2006;101:803-6.

11. Poveda R, Bagán JV, Fernández JM, Sanchis JM. Mental nerve paresthesia associated with endodontic paste within the mandibular canal: report of a case. Oral Surg Oral Med Oral Pathol Oral Radiol Endod. 2006; 102:e46-9.

12. Froes FG, Miranda AM, Abad Eda C, Riche FN, Pires FR. Nonsurgical management of paraesthesia and pain associated with endodontic sealer extrusion into the mandibular canal. Aust Endod J. 2009;35:183-6.

13. Fardal O, Johannessen AC, Morken T. Gingivo-mucosal and cutaneous reactions to amalgam fillings. J Clin Periodontol. 2005;32:430-3. 